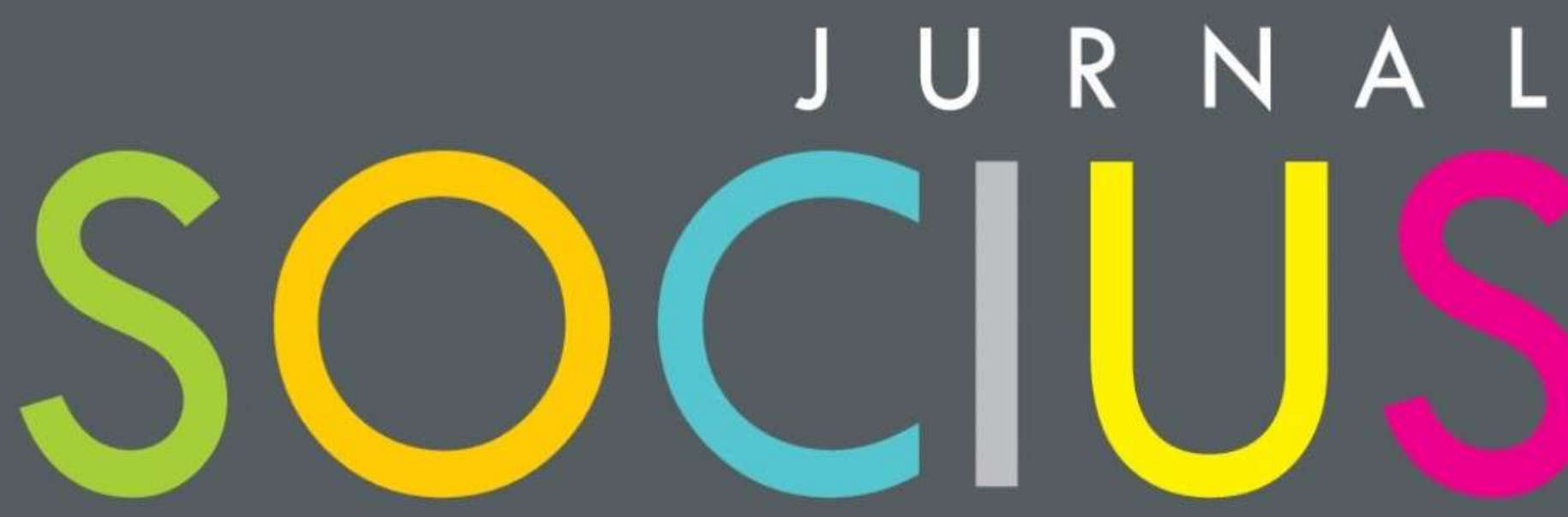

Journal of Sociology Research and Education

DITERBITKAN OLEH :

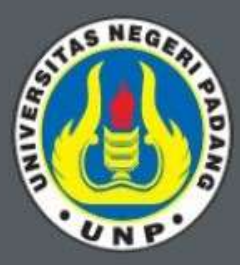

LABOR JURUSAN SOSIOLOGI FAKULTAS ILMU SOSIAL UNIVERSITAS NEGERI PADANG

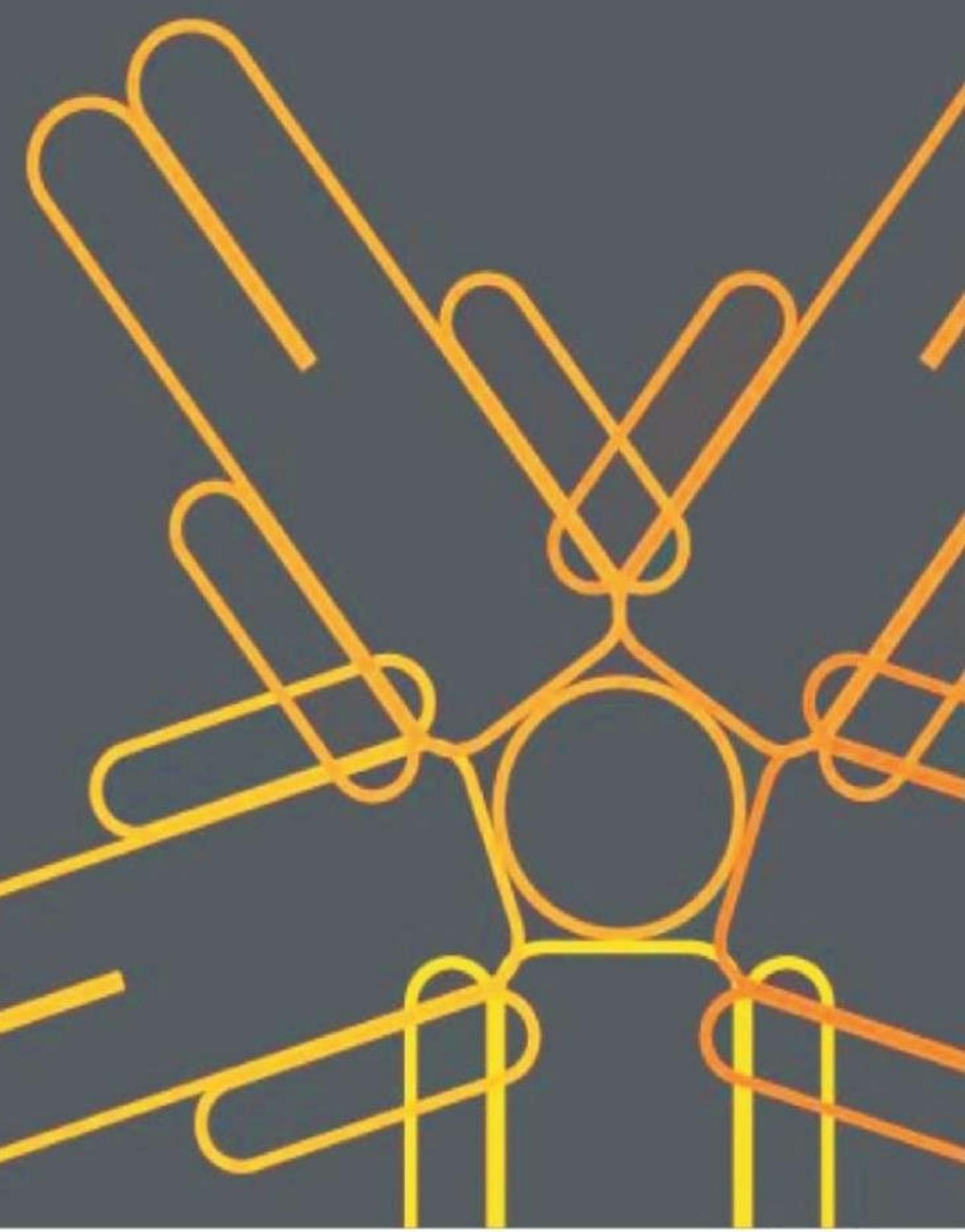




\section{SOCIUS}

Vol. 5, No.2, Th. 2018

ISSN : 2356-4180 (cetak)

2442-8663 (online)

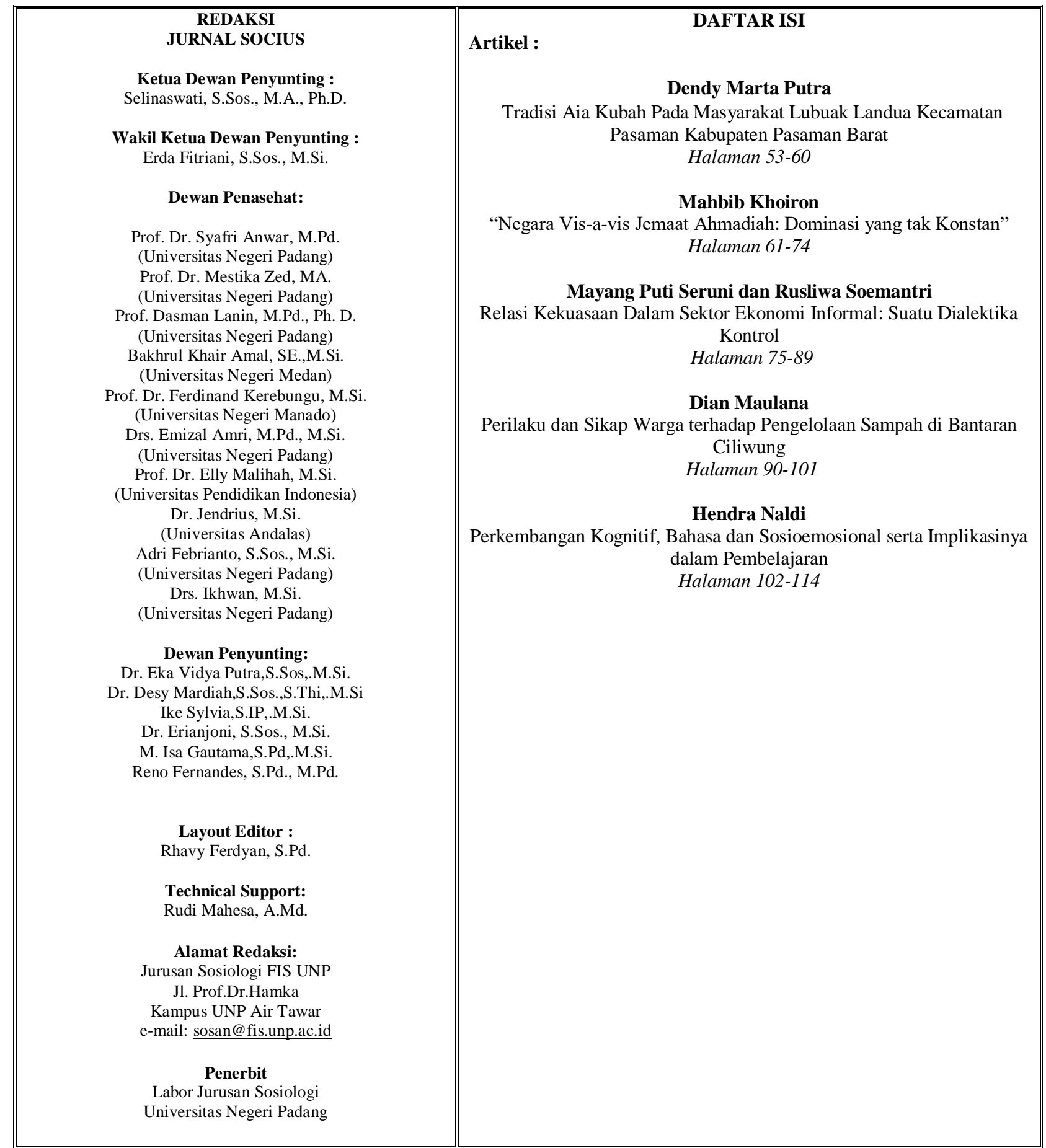




\title{
PERILAKU DAN SIKAP WARGA TERHADAP PENGELOLAAN SAMPAH DI BANTARAN CILIWUNG
}

\author{
Dian Maulana ${ }^{1}$, Afrizal ${ }^{2}$, Irsan Ryanto ${ }^{3}$ \\ 1,2,3 Universitas Andalas \\ Email: dionmaulana@gmail.com
}

\begin{abstract}
Abstrak
Arus urbanisasi ke Jakarta membuat kondisi bantaran Ciliwung semakin memprihatinkan. Para pendatang yang rata-rata kurang berpendidikan dan berpenghasilan rendah, terpaksa tinggal di sepanjang Bantaran sungai yang memang masih kosong. Banyaknya permukiman kumuh di Jakarta menyebabkan bantaran Ciliwung beralih fungsi menjadi "tempat pembuangan sampah". Penelitian ini bertujuan untuk mengkaji hubungan antara sikap dan perilaku warga terhadap pengelolaan sampah di Bantaran Ciliwung, Manggarai-Tebet, Jakarta Selatan. Metode penelitian yang digunakan yaitu deskriptif kualitatif pada penelitian berorientasi kewilayahan pada ruang yang sempit dengan tingkat variasi yang rendah menggunakan skala Likert, Uji Koefisien Regresi Parsial (Uji t) dan Uji Koefisien Regresi Secara Bersama-Sama (Uji F). Hasil penelitian menunjukkan 1) perilaku warga terhadap pengelolaan sampah di bantaran Ciliwung termasuk kategori tidak baik dengan nilai rata-rata $1.1 \mathrm{NC}$; 2) sikap warga terhadap pengelolaan sampah di bantaran Ciliwung termasuk kategori baik dengan nilai rata-rata 3,0 $\mathrm{NC}$; dan 3) koefisien korelasi antara variabel perilaku dan sikap warga dengan pengelolaan sampah $r_{\mathrm{xy}}$ sebesar 0,569. Hubungan yang signifikan dan positif antara perilaku dan sikap warga dengan pengelolaan sampah dari hasil penelitian ini dapat kita artikan bahwa perilaku dan sikap warga berpengaruh terhadap pengelolaan sampah. Temuan penelitian ini berarti bahwa semakin tinggi tingkat pendidikan warga maka akan semakin baik pula dalam pengelolaan sampah di bantaran Ciliwung.
\end{abstract}

Kata Kunci: Perilaku, Sikap, Warga, Sampah, Ciliwung.

\section{Abstract}

Urbanization flows to Jakarta make the condition of the Bantaran Ciliwung banks more alarming. The migrants, who were on average less educated and low-income, were forced to live along the riverbank which was still empty. The large number of slums in Jakarta caused the Bantaran Ciliwung to turn into "garbage dumps". This study aims to examine the relationship between people's attitudes and behavior towards waste management in Bantaran Ciliwung, Manggarai-Tebet, South Jakarta. The research method used is descriptive qualitative in the area-oriented research in a narrow space with a low level of variation using a Likert scale, Partial Regression Coefficient Test (t test) and Test Regression Coefficient Together (Test F). The results of the study showed that 1) the behavior of citizens towards the management of waste at the Bantaran Ciliwung was categorized as not good with an average value of $1.1 \mathrm{NC}$; 2) the attitudes of residents towards waste management at the Bantaran Ciliwung are in the good category with an average value of $3.0 \mathrm{NC}$; and 3) the correlation coefficient between the variable behavior and attitudes of residents with waste management $R_{x y}$ of 0.569 . A significant and positive relationship between the behavior and attitudes of citizens with waste management from the results of this study can we interpret that the behavior and attitudes of citizens influence waste management. The findings of this study mean that the higher the level of education of citizens, the better it will be in waste management at the Bantaran Ciliwung.

Keywords: Behavior, Attitude, Citizens, Trash, Ciliwung

This is an open acces article distributed under the Creative Commons 4.0 Attribution License, wich permits unrestricted use, distribution, and reproduction in any medium provided the original work is properly cited (C2018 by author and Universitas Negeri Padang. 


\section{Latar Belakang}

Urbanisasi atau perpindahan penduduk dari desa ke kota dengan tujuan mencari penghasilan atau pekerjaan yang layak di kota adalah satu akibat dari pembangunan. Urbanisasi menimbulkan peningkatan kebutuhan akan ruang untuk tempat tinggal. Hal ini akan berdampak pada kondisi lahan yang semakin padat. Perubahan pola penggunaan lahan ini telah member dampak sangat nyata terhadap fungsi Daerah Aliran Sungai (DAS) perkotaan (Putra, 2012); (Putra, 2017). Semakin derasnya arus urbanisasi ke Jakarta, membuat kondisi bantaran Ciliwung semakin memprihatinkan. Para pendatang yang berpendidikan dan berpenghasilan rendah, terpaksa tinggal dimana saja yang mungkin, utamanya di sepanjang Bantaran sungai yang memang masih kosong. Banyaknya permukiman di Bantaran Ciliwung menyebabkan beralih fungsi menjadi "tempat pembuangan sampah". Persoalan ini sebenarnya telah terjadi semenjak abad ke-16, dimana pemerintah kolonial sudah mengeluarkan aturan sejak tahun 1630 tentang membuang sampah ke sungai. Ketika itu siapa saja dilarang membuang sampah ke sungai yang mengalir di dalam kota. Aturan tersebut kemudian diundangkan lagi pada tahun 1777 dan 1778 (Isnain, 2017).

Luas lahan bantaran Ciliwung sejak dari hulu sampai hilir, mulai dari pintu air Manggarai sampai ke ujung jembatan Slamet Riyadi membentang lebih dari $6 \mathrm{Ha}$ (Pemerintah DKI Jakarta, 2015). Pertumbuhan penduduk yang terjadi secara alami dan migrasi berpotensi mengubah pola penggunaan lahan menjadi permukiman yang tidak sesuai dengan peruntukkan. Permukiman berubah menjadi kumuh, padat, dan tidak manusiawi dengan kualitas yang rendah dan tidak sehat. Pembangunan rumah tidak layak huni sepanjang bantaran Ciliwung berdampak pada kualitas lingkungan fisik dan non fisik yang tidak sehat. Sebagai daerah yang menjadi pusat perekonomian warga diharapkan permukiman penduduknya sudah memenuhi syarat-syarat lingkungan yang sehat, seperti menggunakan air yang layak untuk digunakan sehari-hari (PDAM), serta lingkungan pemukimannya yang bersih dari pencemaran sampah.

Pemerintah berkewajiban untuk menumbuhkan dan mengembangkan kesadaran warga bertanggungjawab dalam mengelola lingkungan hidup. Upaya ini harus membuat warga sendiri berperan aktif dalam penanggulangan masalah sampah. Warga juga berkewajiban untuk menjaga kebersihan lingkungan karena sadar akan lingkungan yang bersih dapat menciptakan kondisi lingkungan yang optimal bagi kehidupan yang sehat bagi warga secara menyeluruh. Pemerintah melalui Departemen Kesehatan (DEPKES) RI tahun 2004 menjalin kerjasama yang baik dengan berbagai instansi dan telah banyak mendorong berbagai upaya beberapa kegiatan, salah satunya dengan cara gotong royong bersama warga yang telah membawa dampak positif (Suprihatin, 2014). Akan tetapi sampah masih dibuang kedalam Bantara Ciliwung. Adapun tujuan penelitian ini adalah untuk mendeskripsikan perilaku mengelola sampah dan menemukan hubungan antara sikap warga tentang sampah dan perilaku warga dalam mengelola sampah di Bantaran Ciliwung, Manggarai-Tebet, Jakarta Selatan.

\section{Metodologi Penelitian}

\section{Defenisi Operasional Variable, Indikator, Pengukuran dan Instrument}

Perilaku dan sikap warga yang dimaksud dalam penelitian ini adalah terhadap pengelolaan sampah di bantaran Ciliwung Manggarai-Tebet. Adapun indikator perilaku yaitu: i) perhatian; dan ii) tindakan, sedangkan indikator sikap yaitu: i) perhatian; ii) manfaat dan 
keikutsertaan; iii) tanggung jawab; dan iv) tindakan, untuk lebih jelasnya dapat dilihat pada Tabel 3.3 terkait kisi-kisi instrument penelitian.

Teknik pengumpulan data yang dilaksanakan dalam penelitian ini adalah dengan menggunakan daftar pertanyaan atau kuesioner, sedangkan beberapa hal yang tidak mungkin dilakukan dengan kuesioner dilakukan dengan observasi langsung dilapangan (Afrizal, 2008). Agar instrumen menjaring data sesuai dengan yang dibutuhkan, maka perlu mempertimbangkan validitas dan reabilitas instrumen. Instrumen teknik penelitian dalam pengumpulan data yang digunakan adalah dengan menggunakan angket disusun menurut variabel pada penelitian dengan menggunakan skala pengukuran. Angket yang digunakan terdiri dari pernyataan positif dengan 4 alternatif jawaban seperti pada Tabel 2 berikut.

Tabel 1. Kisi-Kisi Instrument Penelitian.

\begin{tabular}{|c|c|c|}
\hline Variabel & Indikator & No. Item \\
\hline \multicolumn{2}{|c|}{ Perilaku warga terhadap pengelolaan sampah } & $1-8$ \\
\hline \multirow{4}{*}{$\begin{array}{l}\text { Sikap warga terhadap } \\
\text { pengelolaan sampah }\end{array}$} & 1. Perhatian & $9-10$ \\
\hline & 2. Manfaat dan keikutsertaan & $11-13$ \\
\hline & 3. Tanggung jawab & $14-17$ \\
\hline & 4. Tindakan & $18-20$ \\
\hline
\end{tabular}

Sumber: Modifikasi Eliza, 2008.

Uji coba instrumen dilakukan untuk melihat validitas dan realibilitas instrumen dalam rangka memenuhi persyaratan instrumen penelitian, maka perlu dilakukan pengujian secara empiris di lapangan dalam bentuk uji coba (try out). Uji coba ini dilakukan pada responden lain diluar responden sebagai sampel penelitian yang sebenarnya. Pelaksanaan uji coba instrumen penelitian secara umum bertujuan untuk mengetahui kualitas instrumen yang telah disusun, sedangkan secara khusus bertujuan untuk mengetahui validitas instrumen dan reliabilitas instrumen.

\section{Teknik analisis data}

Teknik analisis data yang digunakan dalam penelitian ini adalah analisis deskriptif yaitu dengan formula:

Keterangan:

$$
\mathrm{P}=\frac{F}{N} X 100 \%
$$

$\mathrm{P}=$ presentase

$\mathrm{F}=$ Frekwensi jumlah responden

$\mathrm{n}=$ jumlah responden (Sudjana, 2006).

Sedangkan untuk mengukur perilaku dan sikap pengelolaan sampah warga digunakan skala Likert, menurut Nawi dan Khairani (2009) skala Likert umumnya menggunakan 4 tingkatan, ini dilakukan untuk menghindari bias dari penelitian yang dilakukan, dimana skala tersebut yaitu untuk pertanyaan yang bersifat positif dan negatif yang di beri penilaian sebagai berikut:

a. sangat setuju atau selalu dengan bobot 4

b. setuju atau sering dengan bobot 3

c. kurang setuju atau jarang dengan bobot 2

d. tidak setuju atau tidak pernah dengan bobot 1 .

$$
N C=\frac{(A \times 4)+(B \times 3)+(C \times 2)+(D \times 1)}{n}
$$

Keterangan: 
A = Sangat setuju atau sering dengan bobot 4

$\mathrm{B}=$ Kurang setuju atau kadang-kadang dengan bobot 3

$\mathrm{C}=$ Jarang dengan bobot 2

$\mathrm{D}=$ Tidak pernah, dengan bobot 1

$\mathrm{NC}=$ nilai skor

$\mathrm{n}=$ Jumlah responden

$\mathrm{NC} \geq 2,5=$ Baik

$\mathrm{NC} \leq 2,5=$ Tidak Baik (Anwar, 2008).

Menurut Anwar (2008), apabila skor perilaku dan sikap warga rata-rata kurang dari 3 $(<3)$ maka perilaku dan sikap responden terhadap objek itu tidak baik. Sebaliknya apabila skor perilaku dan sikap rata-rata lebih dari $3(>3)$ maka perilaku dan sikap responden terhadap objek itu relatif baik.

\section{Uji Koefisien Regresi Parsial (Uji t)}

Dalam penelitian ini menggunakan uji t, untuk menguji variabel bebas secara satu persatu ada atau tidaknya pengaruh terhadap variabel terikat. Langkah - langkah pengujiannya sebagai berikut :

Menentukan formasi Hipotesis Nihil (H0) dan Hipotesis Alternatif (H1)

Level of significant $(\alpha=0.05)$ Sampel $n=$ jumlah sampel

Menentukan kriteria pengujian

H1 ditolak apabila t hitung $<\mathrm{t}$ table

$\mathrm{H} 0$ ditolak apabila t hitung $>\mathrm{t}$ table

Kesimpulan

Apabila t hitung $>\mathrm{t}$ tabel maka $\mathrm{H} 0$ ditolak, artinya ada pengaruh positif.

Apabila $\mathrm{t}$ hitung $<\mathrm{t}$ tabel maka $\mathrm{H} 0$ diterima, artinya tidak ada pengaruh.

\section{Uji Koefisien Regresi Secara Bersama-Sama (Uji F)}

Pengujian simultan bertujuan untuk mengetahui hubungan variabel independen secara bersama-sama dengan variabel dependen. Hipotesis uji $\mathrm{F}: \mathrm{H} 0=\mathrm{b} 1, \mathrm{~b} 2=0$, variabel independen secara simultan tidak signifikan berhubungan dengan variabel dependen. $\mathrm{Ha}=\mathrm{b} 1$, b2 $\neq 0$, variabel independen secara simultan berhubungan signifikan dengan variabel dependen. Penarikan kesimpulan dilakukan dengan berdasarkan probilitas, jika tingkat signifikannya (a) >0,05 maka semua variabel independen tidak berhubungan signifikan perubahan variabel dependen. Jika tingkat signifikannya (a) $<0,05$ maka semua variabel independen berhubungan signifikan dengan perubahan nilai variabel dependen.

\section{Hasil Penelitian dan Pembahasan}

\section{Perilaku Warga Terhadap Pengelolaan Sampah}

Deskripsi perilaku warga terhadap pengelolaan sampah di bantaran Ciliwung diperoleh melalui penyebaran angket kepada warga di RW 010/RT 01-02 Kelurahan Manggarai-Tebet dan kemudian data-nya diolah menjadi data kualitatif dari 8 pertanyaan kuesioner (No. 1, 2, 3, 4, 5, 6, 7 dan 8) terkait perilaku warga terhadap pengelolaan sampah di bantaran Ciliwung menunjukkan 177 responden menyatakan sangat setuju, 162 responden menyatakan setuju, 280 responden menyatakan kurang setuju, dan 181 responden menyatakan tidak setuju. Untuk lebih jelasnya dapat dilihat pada Gambar 1 dan Tabel 3 berikut. 


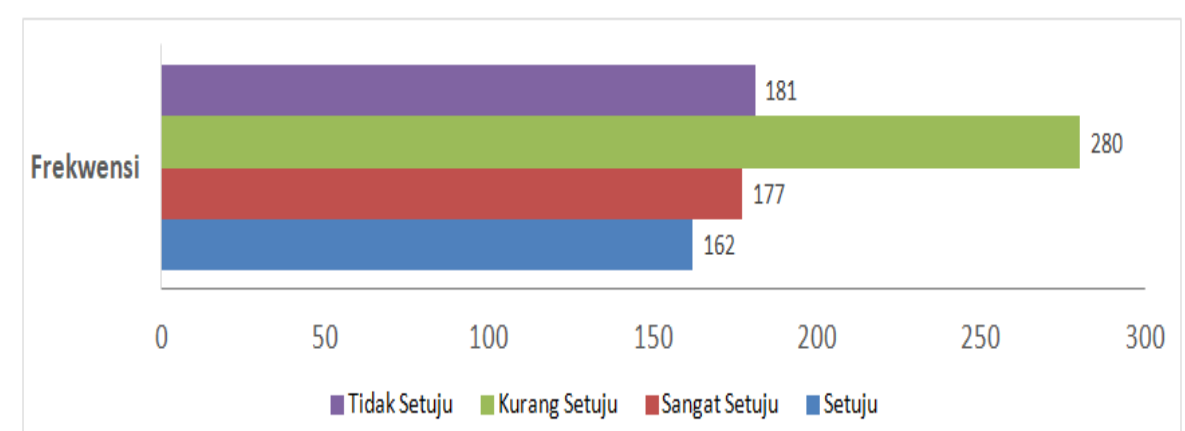

Gambar 1. Grafik perilaku warga dalam pengelolaan sampah.

Tabel 2. Rekapitulasi data perilaku warga dalam pengelolaan sampah.

\begin{tabular}{|c|c|c|c|c|c|c|c|c|c|}
\hline \multirow{3}{*}{ Pertanyaan } & \multicolumn{8}{|c|}{ Frekuensi Persentase jawaban } & \multirow{3}{*}{ NC } \\
\hline & \multicolumn{2}{|c|}{ SS } & \multicolumn{2}{|c|}{$\mathbf{S}$} & \multicolumn{2}{|c|}{$\mathrm{KS}$} & \multicolumn{2}{|c|}{ TS } & \\
\hline & $\mathbf{F}$ & $\%$ & $\mathbf{F}$ & $\%$ & $\mathbf{F}$ & $\%$ & $\mathbf{F}$ & $\%$ & \\
\hline $\begin{array}{l}\text { Apakah anda selalu menjaga } \\
\text { kebersihan halaman rumah dan } \\
\text { bantaran terhadap sampah }\end{array}$ & 22 & $12 \%$ & 50 & $31 \%$ & 6 & $2 \%$ & 22 & $12 \%$ & 1.5 \\
\hline $\begin{array}{l}\text { Apakah anda sering membuang } \\
\text { sampah ke halaman rumah }\end{array}$ & 2 & $1 \%$ & 7 & $4 \%$ & 69 & $25 \%$ & 22 & $12 \%$ & 0.7 \\
\hline $\begin{array}{l}\text { Apakah anda sering membuang } \\
\text { sampah kebantaran }\end{array}$ & 3 & $2 \%$ & 8 & $5 \%$ & 54 & $19 \%$ & 35 & $19 \%$ & 0.6 \\
\hline $\begin{array}{l}\text { Apakah anggota keluarga anda } \\
\text { sering membuang sampah ke } \\
\text { halaman rumah }\end{array}$ & 10 & $6 \%$ & 6 & $4 \%$ & 31 & $11 \%$ & 53 & $29 \%$ & 0.6 \\
\hline $\begin{array}{l}\text { Apakah anggota keluarga anda } \\
\text { sering membuang sampah ke } \\
\text { bantaran }\end{array}$ & 3 & $2 \%$ & 50 & $31 \%$ & 10 & $4 \%$ & 37 & $20 \%$ & 1.1 \\
\hline $\begin{array}{l}\text { Apakah anda pernah } \\
\text { melarang/menegur anggota } \\
\text { keluarga anda yang membuang } \\
\text { sampah ke halaman rumah }\end{array}$ & 66 & $37 \%$ & 25 & $15 \%$ & 3 & $1 \%$ & 6 & $3 \%$ & 2.0 \\
\hline $\begin{array}{l}\text { Apakah anda pernah } \\
\text { melarang/menegur anggota } \\
\text { keluarga anda yang membuang } \\
\text { sampah ke bantaran }\end{array}$ & 36 & $20 \%$ & 8 & $5 \%$ & 53 & $19 \%$ & 3 & $2 \%$ & 1.3 \\
\hline $\begin{array}{l}\text { Apakah anda pernah } \\
\text { melarang/menegur tetangga } \\
\text { anda yang membuang sampah } \\
\text { ke bantaran }\end{array}$ & 35 & $20 \%$ & 8 & $5 \%$ & 54 & $19 \%$ & 3 & $2 \%$ & 1.3 \\
\hline Jumlah & 177 & & 162 & & 280 & & 181 & & \\
\hline Rata-rata & & $100 \%$ & & $100 \%$ & & $100 \%$ & & $100 \%$ & \\
\hline
\end{tabular}

Sumber: Pengolahan Data Primer, 2018.

Berdasarkan Tabel 3 terlihat bahwa perilaku warga terhadap pengelolaan sampah yaitu dengan nilai rata-rata $1.1 \mathrm{NC}$, ini berarti termasuk dalam kategori tidak pro-lingkungan. 


\section{Sikap warga terhadap pengelolaan sampah}

Deskripsi sikap warga terhadap pengelolaan sampah di bantaran Ciliwung dilihat dari 4 pendekatan indikator yaitu: 1) perhatian, 2) manfaat dan keikutsertaan, 3) tanggung jawab, dan 4) tindakan.

\section{Perhatian}

Data mengenai perhatian warga terhadap pengelolaan sampah di bantaran Ciliwung diperoleh melalui penyebaran angket kepada warga di di RW 010/RT 01-02 Kelurahan Manggarai-Tebet dan kemudian data-nya diolah menjadi data kualitatif. Dari 2 pertanyaan kuesioner (No. 9 dan 10) terkait perhatian warga terhadap pengelolaan sampah di bantaran Ciliwung menunjukkan 118 responden menyatakan sangat setuju, 57 responden menyatakan setuju, 15 responden dengan menyatakan kurang setuju, dan 10 responden menyatakan tidak setuju. Untuk lebih jelasnya dapat dilihat pada Gambar 2 dan Tabel 4 berikut.

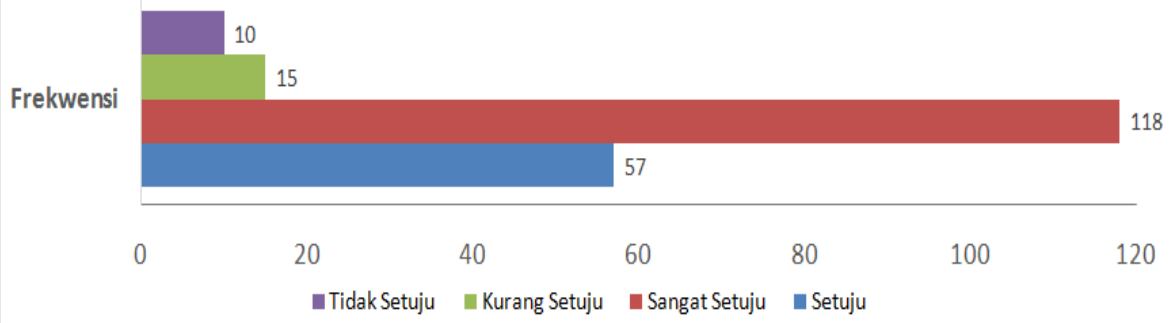

Gambar 2. Grafik sikap perhatian warga terhadap pengelolaan sampah.

Tabel 3. Rekapitulasi data sikap perhatian warga terhadap pengelolaan sampah.

\begin{tabular}{|c|c|c|c|c|c|c|c|c|c|}
\hline \multirow{3}{*}{ Pertanyaan } & \multicolumn{8}{|c|}{ Frekwensi Persentase jawaban } & \multirow{3}{*}{$\mathbf{N C}$} \\
\hline & \multicolumn{2}{|c|}{ SS } & \multicolumn{2}{|c|}{$\mathbf{S}$} & \multicolumn{2}{|c|}{$\mathbf{K S}$} & \multicolumn{2}{|c|}{$\overline{T S}$} & \\
\hline & $\mathbf{F}$ & $\%$ & $\mathbf{F}$ & $\%$ & $\mathbf{F}$ & $\%$ & $\mathbf{F}$ & $\%$ & \\
\hline $\begin{array}{l}\text { Perhatian warga terhadap } \\
\text { dampak air sungai akibat } \\
\text { membuang sampah ke bantaran }\end{array}$ & 58 & $49 \%$ & $\begin{array}{l}2 \\
7\end{array}$ & $47 \%$ & 10 & $67 \%$ & 5 & $50 \%$ & 4.7 \\
\hline $\begin{array}{l}\text { Perhatian warga terhadap } \\
\text { kebersihan halaman rumah } \\
\text { akibat membuang sampah }\end{array}$ & 60 & $51 \%$ & $\begin{array}{l}3 \\
0\end{array}$ & $53 \%$ & 5 & $33 \%$ & 5 & $50 \%$ & 4.3 \\
\hline Jumlah & $\begin{array}{c}11 \\
8\end{array}$ & & $\begin{array}{l}5 \\
7\end{array}$ & & 15 & & 10 & & \\
\hline Rata-rata & & $\begin{array}{c}100 \\
\%\end{array}$ & & $\begin{array}{c}100 \\
\%\end{array}$ & & $\begin{array}{c}100 \\
\%\end{array}$ & & $\begin{array}{c}100 \\
\%\end{array}$ & \\
\hline
\end{tabular}

Sumber: Pengolahan Data Primer, 2018.

Berdasarkan Tabel 4 terlihat bahwa perhatian warga terhadap pengelolaan sampah di bantaran Ciliwung yaitu dengan nilai rata-rata $4.5 \mathrm{NC}$, ini berarti termasuk dalam kategori pro-lingkungan.

\section{Manfaat dan Keikutsertaan}

Data mengenai manfaat dan keikutsertaan warga terhadap pengelolaan sampah di bantaran Ciliwung diperoleh melalui penyebaran angket kepada warga di di RW 010/RT 0102 Kelurahan Manggarai-Tebet dan kemudian data-nya diolah menjadi data kualitatif. Dari 3 
pertanyaan kuesioner (No. 11, 12 dan 13) terkait sikap warga (manfaat dan keikutsertaan) dalam pengelolaan sampah di bantaran Ciliwung menunjukkan 118 responden menyatakan sangat setuju, 57 responden menyatakan setuju, 15 responden dengan menyatakan kurang setuju, dan 10 responden menyatakan tidak setuju. Untuk lebih jelasnya dapat dilihat pada Gambar 3 dan Tabel 4.5 berikut.

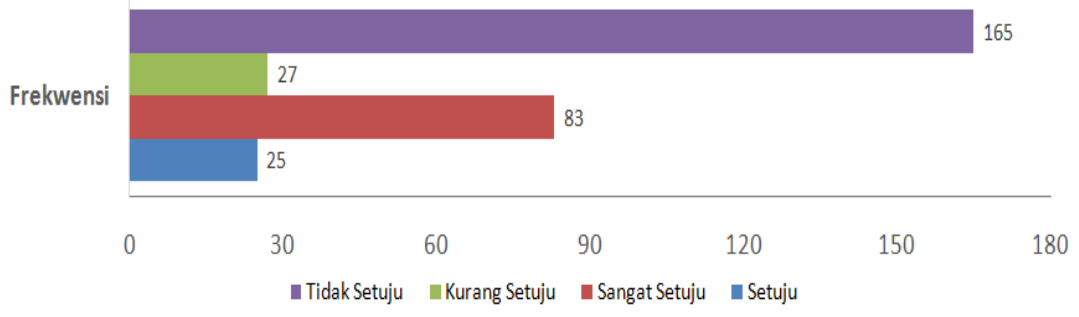

Gambar 3 Grafik manfaat keikutsertaan warga terhadap pengelolaan sampah.

Tabel 4. Rekapitulasi data manfaat keikutsertaan warga terhadap pengelolaan sampah.

\begin{tabular}{|c|c|c|c|c|c|c|c|c|c|}
\hline \multirow{3}{*}{ Pertanyaan } & \multicolumn{8}{|c|}{ Frekwensi Persentase jawaban } & \multirow{3}{*}{ NC } \\
\hline & \multicolumn{2}{|c|}{ SS } & \multicolumn{2}{|c|}{$\mathbf{S}$} & \multicolumn{2}{|c|}{ KS } & \multicolumn{2}{|c|}{ TS } & \\
\hline & $\mathbf{F}$ & $\%$ & $\mathbf{F}$ & $\%$ & $\mathbf{F}$ & $\%$ & $\mathbf{F}$ & $\%$ & \\
\hline $\begin{array}{l}\text { Adakah manfaat dari } \\
\text { pencemaran sampah terhadap } \\
\text { bantaran }\end{array}$ & 4 & $5 \%$ & 3 & $12 \%$ & $\begin{array}{l}1 \\
1\end{array}$ & $41 \%$ & 82 & $\begin{array}{l}50 \\
\%\end{array}$ & 1.4 \\
\hline $\begin{array}{l}\text { Adakah manfaat dari kondisi } \\
\text { air bantaran tidak layak dipakai } \\
\text { untuk mandi dan mencuci }\end{array}$ & $\begin{array}{l}7 \\
7\end{array}$ & $93 \%$ & $\begin{array}{l}1 \\
4\end{array}$ & $56 \%$ & 3 & $11 \%$ & 4 & $2 \%$ & 5.7 \\
\hline $\begin{array}{l}\text { Adakah keikutsertaan warga } \\
\text { dalam menjaga kebersihan } \\
\text { lingkungan halaman rumah dan } \\
\text { bantaran }\end{array}$ & 2 & $2 \%$ & 8 & $32 \%$ & $\begin{array}{l}1 \\
3\end{array}$ & $48 \%$ & 79 & $\begin{array}{l}48 \\
\%\end{array}$ & 1.9 \\
\hline \multirow{2}{*}{ Jumlah } & 8 & & 2 & & 2 & & 16 & & \multirow{3}{*}{3.5} \\
\hline & 3 & & 5 & & 7 & & 5 & & \\
\hline Rata-rata & & $100 \%$ & & $100 \%$ & & $100 \%$ & & $\begin{array}{c}10 \\
0 \%\end{array}$ & \\
\hline
\end{tabular}

Sumber: Pengolahan Data Primer, 2018.

Berdasarkan Tabel 5 terlihat bahwa manfaat dan keikutsertaan warga terhadap pengelolaan sampah di bantaran Ciliwung yaitu dengan nilai rata-rata $3.5 \mathrm{NC}$, ini berarti termasuk dalam kategori pro-lingkungan.

\section{Tanggung Jawab}

Data mengenai tanggung jawab warga terhadap pengelolaan sampah di bantaran Ciliwung diperoleh melalui penyebaran angket kepada warga di RW 010/RT 01-02 Kelurahan Manggarai-Tebet dan kemudian data-nya diolah menjadi data kualitatif. Dari 4 pertanyaan kuesioner (No. 14, 15, 16 dan 17) terkait tanggung jawab warga terhadap pengelolaan sampah di bantaran Ciliwung menunjukkan 118 responden menyatakan sangat setuju, 233 responden menyatakan setuju, 30 responden dengan menyatakan kurang setuju, dan 19 responden 
menyatakan tidak setuju. Untuk lebih jelasnya dapat dilihat pada Gambar 4 dan Tabel 6 berikut.

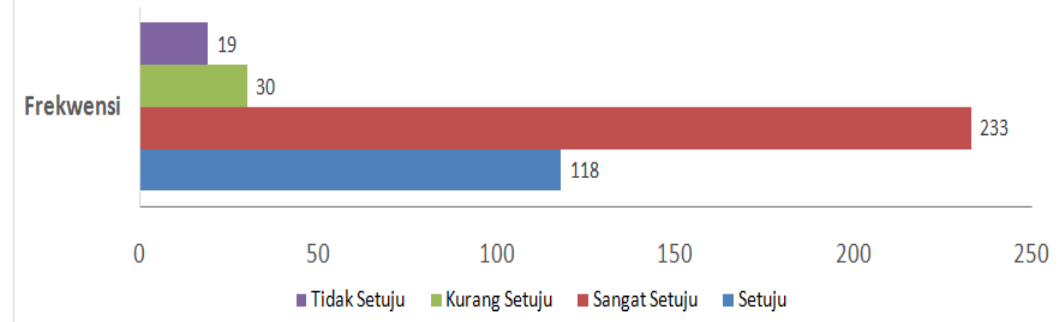

Gambar 4 Grafik tanggung jawab warga terhadap pengelolaan sampah.

Tabel 5. Rekapitulasi data tanggung jawab warga terhadap pengelolaan sampah.

\begin{tabular}{|c|c|c|c|c|c|c|c|c|c|}
\hline \multirow{3}{*}{ Pertanyaan } & \multicolumn{8}{|c|}{ Frekwensi Persentase jawaban } & \multirow{3}{*}{ NC } \\
\hline & \multicolumn{2}{|c|}{ SS } & \multicolumn{2}{|c|}{$\mathbf{S}$} & \multicolumn{2}{|c|}{ KS } & \multicolumn{2}{|c|}{ TS } & \\
\hline & $\mathbf{F}$ & $\%$ & $\mathbf{F}$ & $\%$ & $\mathbf{F}$ & $\%$ & $\mathbf{F}$ & $\%$ & \\
\hline $\begin{array}{l}\text { Adakah tanggung jawab saudara } \\
\text { dalam menjaga } \\
\text { lingkungan bantaran }\end{array}$ & 52 & $44 \%$ & 45 & $19 \%$ & 5 & $17 \%$ & 3 & $16 \%$ & 2.3 \\
\hline $\begin{array}{l}\text { Adakah tanggung jawab saudara } \\
\text { dalam menjaga kondisi } \\
\text { lingkungan halaman rumah }\end{array}$ & 52 & $44 \%$ & 31 & $13 \%$ & $\begin{array}{l}1 \\
2\end{array}$ & $40 \%$ & 2 & $11 \%$ & 3.2 \\
\hline 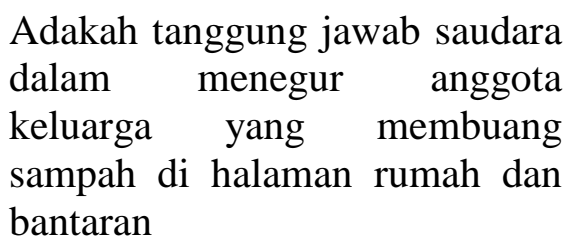 & 10 & $8 \%$ & 68 & $29 \%$ & $\begin{array}{l}1 \\
0\end{array}$ & $33 \%$ & $\begin{array}{l}1 \\
0\end{array}$ & $53 \%$ & 2.0 \\
\hline $\begin{array}{l}\text { Adakah tanggung jawab saudara } \\
\text { dalam menegur tetangga atau } \\
\text { warga yang membuang sampah } \\
\text { di halaman rumah dan bantaran }\end{array}$ & 4 & $3 \%$ & 89 & $38 \%$ & 3 & $10 \%$ & 4 & $21 \%$ & 1.5 \\
\hline Jumlah & 11 & & 23 & & 3 & & 1 & & \\
\hline Jumian & 8 & & 3 & & 0 & & 9 & & 3 \\
\hline Rata-rata & & $\begin{array}{c}100 \\
\%\end{array}$ & & $\begin{array}{c}100 \\
\%\end{array}$ & & $\begin{array}{c}100 \\
\%\end{array}$ & & $\begin{array}{c}100 \\
\%\end{array}$ & \\
\hline
\end{tabular}

Sumber: Pengolahan Data Primer, 2018.

Berdasarkan Tabel 6 terlihat bahwa tanggung jawab warga terhadap pengelolaan sampah di bantaran Ciliwung yaitu dengan nilai rata-rata $2.3 \mathrm{NC}$, ini berarti termasuk dalam kategori tidak pro-lingkungan.

\section{Tindakan}

Data mengenai tindakan warga terhadap pengelolaan sampah di bantaran Ciliwung diperoleh melalui penyebaran angket kepada warga di RW 010/RT 01-02 Kelurahan Manggarai-Tebet dan kemudian data-nya diolah menjadi data kualitatif. Dari 7 pertanyaan kuesioner (No. 18, 19 dan 20) terkait tindakan warga terhadap pengelolaan sampah di 
bantaran Ciliwung menunjukkan 20 responden menyatakan sangat setuju, 66 responden menyatakan setuju, 96 responden menyatakan kurang setuju, dan 118 responden menyatakan tidak setuju. Untuk lebih jelasnya dapat dilihat pada dan Gambar 5 dan Tabel 7 berikut.

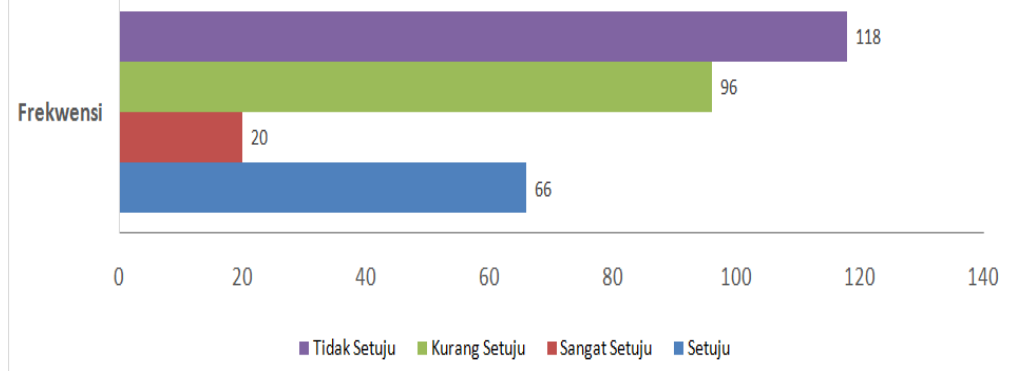

Gambar 5. Grafik tindakan warga terhadap pengelolaan sampah.

Tabel 7. Rekapitulasi data tindakan warga terhadap pengelolaan sampah.

\begin{tabular}{|c|c|c|c|c|c|c|c|c|c|}
\hline \multirow{3}{*}{ Pertanyaan } & \multicolumn{8}{|c|}{ Frekuensi Persentase jawaban } & \multirow{3}{*}{$\mathrm{NC}$} \\
\hline & \multicolumn{2}{|c|}{$\mathbf{S S}$} & \multicolumn{2}{|c|}{$\mathbf{S}$} & \multicolumn{2}{|c|}{$\mathbf{K S}$} & \multicolumn{2}{|c|}{ TS } & \\
\hline & $\mathbf{F}$ & $\%$ & $\mathbf{F}$ & $\%$ & $\mathbf{F}$ & $\%$ & $\mathbf{F}$ & $\%$ & \\
\hline $\begin{array}{l}\text { Membuang sampah ke bantaran } \\
\text { perilaku wajar }\end{array}$ & 2 & $10 \%$ & 6 & $9 \%$ & 8 & $8 \%$ & 84 & $71 \%$ & 0.8 \\
\hline $\begin{array}{l}\text { Membuang sampah ke bantaran } \\
\text { cara yang mudah membuang } \\
\text { sampah }\end{array}$ & 5 & $25 \%$ & 12 & $18 \%$ & 77 & $80 \%$ & 6 & $5 \%$ & 3.2 \\
\hline $\begin{array}{l}\text { Membuang sampah ketempat } \\
\text { pembuangan sampah yang } \\
\text { disediakan sulit }\end{array}$ & 13 & $65 \%$ & 48 & $73 \%$ & 11 & $11 \%$ & 28 & $24 \%$ & 5.0 \\
\hline Jumlah & 20 & & 66 & & 96 & & 118 & & \\
\hline Rata-rata & & $\begin{array}{c}100 \\
\%\end{array}$ & & $\begin{array}{c}100 \\
\%\end{array}$ & & $\begin{array}{c}100 \\
\%\end{array}$ & & $\begin{array}{c}100 \\
\%\end{array}$ & 3.0 \\
\hline
\end{tabular}

Sumber: Pengolahan Data Primer, 2018.

Berdasarkan Tabel 4.8 terlihat bahwa tindakan warga terhadap pengelolaan sampah di bantaran Ciliwung yaitu dengan nilai rata-rata 3.0 NC, ini berarti termasuk dalam kategori pro-lingkungan.

\section{Hasil Pengujian Hipotesis}

Setelah uji persyaratan analisis dilakukan dan ternyata semua skor tiap variabel penelitian memenuhi persyaratan untuk dilakukan pengujian statistik lebih lanjut, maka selanjutnya dilakukan pengujian hipotesis. Dalam penelitian terdapat 1 hipotesis penelitian, yaitu (ada atau tidak ada) hubungan antara perilaku dan sikap warga terhadap pengelolaan sampah di bantaran Ciliwung. Hipotesis yang diajukan adalah terdapat hubungan yang signifikan dan positif antara perilaku dan sikap warga terhadap pengelolaan sampah. Dari hasil regresi linear sederhana terhadap data penelitian, hasil analisis hubungan perilaku dan sikap warga terhadap pengelolaan sampah diperoleh seperti Tabel 8 berikut.

Tabel 8. Analisis regresi sederhana antara variabel perilaku dan sikap warga. 


\begin{tabular}{|c|c|c|c|c|c|c|c|}
\hline \multirow{3}{*}{$\begin{array}{c}\text { Variabe } \\
1\end{array}$} & \multirow{3}{*}{$\begin{array}{c}\text { Koefisien } \\
\text { Regresi }\end{array}$} & \multirow{3}{*}{$\begin{array}{l}\text { Standar } \\
\text { Eror }\end{array}$} & \multicolumn{3}{|c|}{$\mathbf{t}$} & \multicolumn{2}{|c|}{ Hipotesis } \\
\hline & & & \multirow[b]{2}{*}{ Hitung } & \multicolumn{2}{|c|}{ Tabel } & \multirow[b]{2}{*}{ Ho } & \multirow[b]{2}{*}{ H1 } \\
\hline & & & & $\begin{array}{c}\alpha \\
=\mathbf{0 , 0 5}\end{array}$ & $\begin{array}{c}\alpha \\
=\mathbf{0 , 0 1}\end{array}$ & & \\
\hline $\mathrm{X}_{1}$ & 0,5264 & 0,1055 & 4,989 & 2,66 & 2.39 & - & $\sqrt{ }$ \\
\hline \multicolumn{2}{|c|}{ Constanta } & $=12,64$ & & & & & \\
\hline \multicolumn{2}{|c|}{ Standar Error of East } & $=2,803$ & & & & & \\
\hline \multicolumn{2}{|c|}{ r.square } & $=0,3237$ & & & & & \\
\hline \multicolumn{2}{|l|}{$\mathrm{r}$} & $=0,569$ & & & & & \\
\hline
\end{tabular}

Sumber : Pengolahan Data Primer, 2018.

Berdasarkan analisis regresi linier sederhana dari data penelitian diperoleh koefisien regresi 0,5264 dan konstanta 12,645. Dengan demikian bentuk hubungan antara kedua variabel dapat disajikan dalam persamaan regresi $\hat{Y}=12,645+0,5264 \mathrm{X}_{1}$. Hasil pengujian

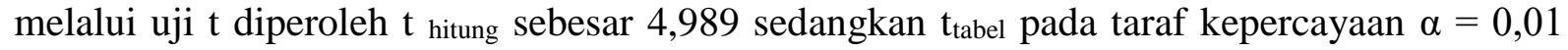
sebesar 2,39 kekuatan hubungan sebesar 0,323 antara variabel perilaku dan sikap warga terhadap pengelolaan sampah, kekuatan hubungan tersebut menunjukan bahwa perilaku dan sikap warga memberi kontribusi sebesar 32,3\%. Dengan demikian terbukti bahwa koefisien tersebut berarti atau hipotesis yang diajukan diterima. Selanjutnya di uji menggunakan uji F adapun hasilnya dapat dilihat pada Tabel 9 berikut.

Tabel 8. Analisis varians variabel perilaku dan sikap warga terhadap pengelolaan sampah.

\begin{tabular}{lllllll}
\hline \multicolumn{1}{c}{ Source } & $\begin{array}{l}\text { Sum Of } \\
\text { Square }\end{array}$ & DF & $\begin{array}{c}\text { Mean } \\
\text { Square }\end{array}$ & Fo & \multicolumn{2}{c}{ F tabel } \\
& \multicolumn{1}{c}{ Rqu $\mathbf{0 , 0 5}$} & $\boldsymbol{\alpha}=\mathbf{0 , 0 1}$ \\
\hline Regression & 195,547 & 1 & 195,547 & 24,889 & 4,027 & 7,12 \\
Residual & 408,5452 & 52 & 7,8566 & & & \\
\hline Total & 604,0926 & 53 & & & & \\
\hline
\end{tabular}

Sumber : Pengolahan Data Primer, 2018.

Berdasarkan Tabel 9 di atas diperoleh harga $\mathrm{F}$ hitung sebesar 24,889, harga ini lebih besar dibandingkan dengan harga $\mathrm{F}$ tabel dengan $\mathrm{DF}$ pembilang 1 dan penyebut 52 pada taraf kepercayaan $\alpha=0,05$ sebesar 4,027 dan $\alpha=0,01$ sebesar 7,12, dengan membandingkan $\mathrm{F}$ hitung dengan $\mathrm{F}$ tabel tersebut diketahui bahwa koefisien regresi signifikan karena $\mathrm{F}$ hitung lebih besar dari $\mathrm{F}_{\text {tabel. }}$.

Tabel 9. Analisis keberartian koefisien korelasional rxy.

\begin{tabular}{lccc}
\hline & \multirow{2}{*}{$\mathbf{r}_{\mathbf{x} 1 \mathbf{y}}$} & \multicolumn{2}{c}{$\mathbf{r}$ tabel pada taraf signifikan } \\
& & $\boldsymbol{\alpha} \mathbf{0 , 0 5}$ & $\boldsymbol{\alpha ~ 0 , 0 1}$ \\
\hline 0,569 & 0,26 & \multicolumn{2}{c}{0,345} \\
\hline
\end{tabular}

Sumber : Pengolahan Data Primer, 2018.

Hasil perhitungan koefisien korelasi antara variabel perilaku dan sikap warga terhadap pengelolaan sampah $\mathbf{r}_{\mathrm{xy}}$ sebesar 0,569. Hasil pengujian menunjukan terdapat hubungan yang signifikan dan positif antara perilaku dan sikap warga terhadap pengelolaan sampah melalui model regresi $=\hat{Y}=12,645+0,5264 \mathrm{X}_{1}$. Untuk lebih jelasnya dapat dilihat pada Gambar grafik 6 berikut. 


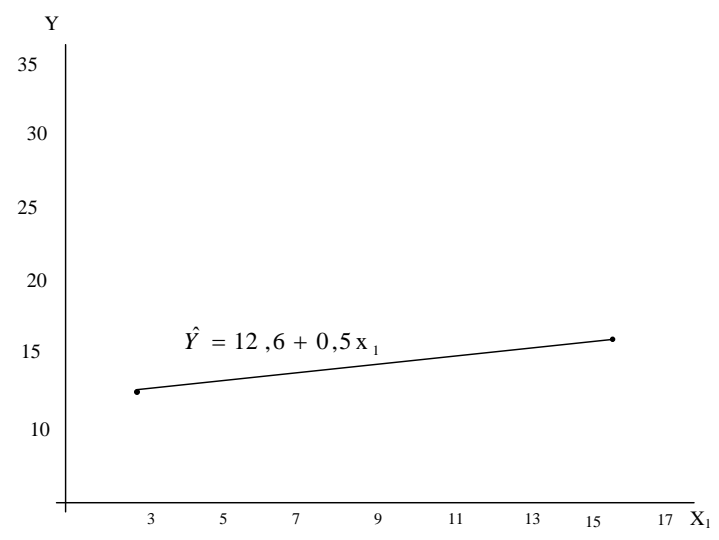

Keterangan : $\mathrm{Y}=$ Pengelolaan Sampah

$\mathrm{X}_{1}=$ Perilaku dan Sikap Warga

\section{Gambar 6. Hubungan antara perilaku dan sikap warga terhadap pengelolaan sampah.}

Apabila pengontrolan dilakukan terhadap variabel bebas lainnya, maka diperoleh koefisien korelasi partial antara perilaku dan sikap $\left(\mathrm{X}_{1}\right)$ dengan pengelolaan sampah $(\mathrm{Y})$ sebesar 0,239. Dalam hal sekaligus menerima hipotesis nol yang menyatakan terdapat hubungan antara perilaku dan sikap warga terhadap pengelolaan sampah. Ini berarti perilaku dan sikap warga merupakan faktor yang penting terhadap pengelolaan sampah di bantaran Ciliwung RW 010/RT 01-02 Kelurahan Manggarai-Tebet.

\section{Penutup}

Berdasarkan hasil penelitian yang penulis lakukan, maka dapat diambil kesimpulan bahwa Perilaku warga terhadap pengelolaan sampah di bantaran Ciliwung dilihat dari indikator perilaku warga terhadap pengelolaan sampah menunjukkan nilai negatif, dari hasil tersebut terlihat bahwa kepedulian dan kesadaran warga dalam pengelolaan sampah termasuk kurang baik dengan nilai rata-rata 1.1 NC. Sedangkan sikap warga terhadap pengelolaan sampah di bantaran Ciliwung dilihat dari indikator 1) perhatian, 2) manfaat dan keikutsertaan, dan 4) tindakan menunjukkan nilai positif dan indikator 3) tanggung jawab menunjukkan nilai negatif, dari hasil rata-rata terkait penilaian sikap warga terhadap pengelolaan sampah menunjukkan kepedulian dan kesadaran warga termasuk baik dengan nilai rata-rata 3.0 NC. Terdapat hubungan yang signifikan dan positif antara perilaku dan sikap warga terhadap pengelolaan sampah, dimana koefisien korelasi antara variabel perilaku dan sikap warga dengan pengelolaan sampah $\left(\mathrm{r}_{\mathrm{xy}}\right)$ sebesar 0,569 ini menunjukkan bahwa semakin tinggi tingkat pendidikan warga, maka akan semakin baik pula dalam pengelolaan sampah di bantaran Ciliwung.

\section{Daftar Pustaka}

Afrizal. (2008). Pengantar Metode Penelitian Kualitatif. Padang: Laboratorium Sosiologi FISIP Universitas Andalas.

Anwar, S. (2008). Penilaian berbasis kompetensi. Padang: UNP Press.

Departemen Kesehatan [DEPKES] RI. (2004). Sistem Kesehatan Nasional. Jakarta.

Eliza, W. (2008). Partisipasi Warga Terhadap Kesehatan Lingkungan Pemukiman Di Kenagarian Padang Mangek Kecamatan Rambatan Kabupaten Tanah Datar. Skripsi, UNP. 
Hariyanto, A. (2010). Strategi Penanganan Kawasan Kumuh Sebagai Upaya Menciptakan Lingkungan Perumahan dan Permukiman yang Sehat (Contoh Kasus: Kota Pangkalpinang). Jurnal Perencanaan Wilayah dan Kota UNISBA, 7(2), 11.

Isnain, F. (2017). Permukiman dan Permasalahan Sepanjang Ciliwung. Data dan Laporan Dinas Perpustakaan dan Kearsipan. [online]. Tersedia: http://dispusip.jakarta.g o.id/?p=4107 [Diakses tanggal 10 Februari 2018].

Kantor Kelurahan Manggarai-Tebet, Jakarta Selatan. (2017). Jumlah Penduduk Kelurahan Manggarai Tahun 2016. Pemerintah DKI Jakarta.

Nawi, M \& Khairani. (2009). Panduan Penyusunan Proposal dengan Mudah. Padang: Yayasan Jihadul Khair Center.

Pemerintah Daerah Khusus Ibu Kota Jakarta. (2015). Data penduduk sepanjang Bantaran Ciliwung Kelurahan Manggarai. Jakarta: Pemerintah Daerah Khusus Ibu Kota Jakarta.

Putra, A. (2012). Studi Erosi Lahan Pada DAS Air Dingin Bagian Hulu di Kota Padang. Skripsi, Universitas Negeri Padang.

Putra, A. (2017). Evaluasi Kesesuaian Pemanfaatan Ruang Pada Kawasan Pesisir Teluk Bungus Kota Padang. Tesis, Pascasarjana Universitas Andalas.

Sudjana, N. (2006). Penelitian dan Nilai Pendidikan. Bandung: Sinar Baru Algensindo

Soemirat, J. (2007). Pencemaran Lingkungan. Jakarta: Rineka Cipta.

Undang-Undang (UU) Nomor 23 Tahun 1992. Jakarta: LN 1992/100; TLN No. 3495. 